Brit. F. vener. Dis. (1970) 47, 27

\title{
Direct and delayed methods of immunofluorescent diagnosis of gonorrhoea in women
}

\author{
R. N. T. THIN, I. A. WILLIAMS, AND C. S. NICOL \\ Department of Venereology, St. Thomas's Hospital, London
}

Deacon and his colleagues were the first to demonstrate Neisseria gonorrhoeae by the immunofluorescent or fluorescent antibody (FA) technique (Deacon, Peacock, Freeman, and Harris, 1959; Deacon, Peacock, Freeman, Harris, and Bunch, 1960). They reported a direct method for FA staining of smears of patients' secretions, and a delayed method in which patients' specimens were cultured and smears for FA staining were taken from the culture plates after incubation. They reported that the direct method gave fewer positive results than the delayed method which gave the same yield as routine cultures.

Various studies have since been reported. For instance, Fry and Wilkinson (1964) found the direct FA staining method gave more positive results than routine cultures. Lind (1967), on the other hand, reported that the delayed FA method gave more positive findings than routine cultures, but that the direct method was much less satisfactory, giving slightly fewer positive findings than Gram-stained smears.

Most of the published reports concern special studies. In 1968 the direct FA staining method was started in this department for the routine investigation of women attending after sexual contact with a man suffering from gonorrhoea. The early results were reported by Thin (1970). The direct FA technique was continued and in 1969 the delayed method was also introduced for routine investigation. The purpose of this paper is to report the first group of patients studied by both methods.

\section{Material and methods \\ OPTICAL EQUIPMENT}

A Gillett and Sibert Conference Research Microscope, with a 100 watt iodine quartz lamp, a dark ground condenser, and a monocular head, was used for this work. A Turner interference primary filter and an Ilford number 108 secondary filter were used. Smears were scanned with $a \times 10$ objective and suspicious areas studied using a $\times 100$ objective with an iris diaphragm.

\section{STAINING MATERIALS}

These were as described by Thin (1970). Rabbit antigonococcal serum conjugated with fluorescein isothiocyanate was obtained from Difco laboratories. Naphthalene black in a concentration of $10 \mathrm{mg} . / \mathrm{ml}$. was diluted $\rightarrow$ just before use to $3 \mathrm{mg} . / \mathrm{ml}$. in pooled human serum obtained from the hospital microbiology department.

\section{STAINING TECHNIQUE}

Specimens for FA staining were thinly spread within a half-inch diameter circle engraved on a clean glass slides Smears were dried in air and heat-fixed in a flame.

Equal parts of antigonococcal fluorescein conjugat and naphthalene black in human serum were mixed, ang a drop of the mixture was spread over the smear. Slides were then incubated at $36^{\circ} \mathrm{C}$. for 10 minutes, washed for 10 minutes in phosphate buffered saline ( $\mathrm{pH} \mathrm{7 \cdot 2)}$ with one change, and rinsed in distilled water. They were dried in air and mounted under buffered glycerin.

\section{SPECIMENS}

Smears for direct FA staining were made from urethral and cervical secretions. Specimens for Gram-staining and culture were taken from the urethra, cervix, and rectum. Urethral and cervical material was plated directly on to agar enriched with lysed horse blood. Rectal cultures were made directly on to lysed horse blood agar containing $\delta$ polymyxin and ristocetin as described by Scott and $₹$ Stone (1966). Urethral and cervical culture plates were $\mathrm{O}$ examined after 16 to $24 \mathrm{hrs}$ ' incubation. If suspicious looking colonies were visible macroscopically they were $\frac{D}{0}$ picked off with a platinum loop and a smear was prepared for FA staining. If no colonies were visible the loop was $\mathrm{N}$ passed over the beginning of the line of inoculation on the plate. Positive routine cultures were identified by the $N$ typical appearance of the colonies, by positive oxidase $N$ reaction, and by sugar fermentation tests.

Specimens collected from the vagina were examined for Candida albicans and Trichomonas vaginalis, and in all cases serum tests for syphilis were performed.

\section{Results}

\section{LABORATORY STUDIES}

Since the first report on this staining method (Thin, $\stackrel{\mathbb{Q}}{\mathbb{Q}}$ 1970), two more strains of Neisseria meningitidis have $\bar{\sigma}$ been examined. They both fluoresced brightly but 
were not as brilliant as $N$. gonorrhoeae from which they were readily distinguished. There was no fluorescence with a further 28 strains of Staphylococcus aureus, 41 strains of Staphylococcus albus, and ten strains of streptococci. Apart from the meningococci, all the organisms were isolated from the genital tract.

\section{CLINICAL STUDIES}

The findings in 157 female patients are presented; all had recently had sexual contact with a man suffering from gonorrhoea. At the first visit to the clinic gonorrhoea was diagnosed by one or more methods in $130(82.8$ per cent) of the women (Table I). Patients with negative results to investigations at their first visit were asked to return, and those in whom the findings remained negative were asked to attend a total of four times for further investigation. Gonorrhoea was diagnosed in ten of the 27 patients attending a second time and in four of the fifteen attending a third time, but in four of those attending a fourth time the results remained negative (Table I). Thus 144 cases were diagnosed (91.1 per cent.).

TABLE I Overall results in 157 female patients

\begin{tabular}{llllll}
\hline Visit & & $1 s t$ & $2 n d$ & $3 r d$ & $4 t h$ \\
\cline { 1 - 3 } \cline { 4 - 6 } Number diagnosed & & 130 & 10 & 4 & 0 \\
Number attended & 157 & 27 & 15 & 4 \\
\hline
\end{tabular}

At each visit the delayed FA method gave more positive results than other methods, and all cases diagnosed at second and third visits were positive by FA techniques alone (Table II). 38 cases $(24 \cdot 2$ per cent.) were diagnosed by FA tests alone, $24(15.3$ per cent.) at the first visit and fourteen ( 8.9 per cent.) at subsequent visits (Table III). The numbers

TABLE II Methods by which gonorrhoea was diagnosed at each visit

\begin{tabular}{lllllll}
\hline Method & $\begin{array}{l}\text { Visit } \\
1 \text { st }\end{array}$ & 2nd & 3rd & 4th & Total \\
\cline { 3 - 5 } \cline { 3 - 5 } Direct FA & & 119 & 5 & 2 & 0 & 126 \\
Delayed FA & 125 & 9 & 4 & 0 & 138 \\
Gram stain & 84 & 0 & 0 & 0 & 84 \\
Culture & 85 & 0 & 0 & 0 & 85 \\
\hline
\end{tabular}

TABLE III Patients positive by FA tests alone

\begin{tabular}{|c|c|c|c|}
\hline Method & $\begin{array}{l}\text { Visit } \\
1 \text { st }\end{array}$ & Subsequent & Total \\
\hline $\begin{array}{l}\text { Direct and delayed } \\
\text { Direct alone } \\
\text { Delayed alone }\end{array}$ & $\begin{array}{r}17 \\
2 \\
5\end{array}$ & $\begin{array}{l}6 \\
1 \\
7\end{array}$ & $\begin{array}{r}23 \\
3 \\
12\end{array}$ \\
\hline Total & 24 & 14 & 38 \\
\hline
\end{tabular}

positive by each method were 126 by the direct FA technique, 138 by the delayed FA technique, 84 by Gram-stained smears, and 85 by cultures.

The patients were divided into primary contacts, who appeared to be their male partner's source of infection, and secondary contacts, who appeared to have been infected by the partner after he had acquired gonorrhoea. Of those diagnosed at their first visit, 72 were primary and 52 secondary contacts (Table IV). On the other hand, among those diagnosed at a subsequent visit, four were primary and ten secondary contacts. Six of the patients in whom the results remained negative were primary and five secondary contacts. Eight patients could not be satisfactorily classified.

TABLE IV Primary and secondary contacts

\begin{tabular}{|c|c|c|c|c|}
\hline Contact & Primary & Secondary & Doubtful & Total \\
\hline $\begin{array}{l}\text { Diagnosed at first visit } \\
\text { at later visit } \\
\text { Not diagnosed }\end{array}$ & $\begin{array}{r}72 \\
4 \\
6\end{array}$ & $\begin{array}{r}52 \\
10 \\
5\end{array}$ & $\begin{array}{l}6 \\
0 \\
2\end{array}$ & $\begin{array}{r}130 \\
14 \\
13\end{array}$ \\
\hline Total & 82 & 67 & 8 & 157 \\
\hline
\end{tabular}

\section{Discussion}

\section{LABORATORY FINDINGS}

All strains of $N$. gonorrhoeae examined by this method fluoresced brightly. As well as the two strains of $N$. meningitidis reported here, Thin (1970) studied nine strains; they all stained brightly but not as brightly as gonococci from which they were readily distinguished. Hare (1969), using a similar staining method, reported strains of meningococci which fluoresced as brightly as gonococci, and others have made similar observations. One possible explanation for our experience is that we use a higher concentration of naphthalene black than most other workers.

No fluorescence was observed among the various strains of staphylococci and streptococci examined. Thin (1970) also reported a number of strains of various organisms which did not fluoresce. The findings here support his view that this method is specific for N. gonnorrhoeae.

\section{CLINICAL FINDINGS}

At the first set of examinations 130 cases $(82.8$ per cent.) were diagnosed by one or more methods, and these together with those diagnosed at subsequent examinations totalled 144 (91.1 per cent.). In the last report from this department (Thin, 1970), 76.9 per cent. of 325 similar cases in women were diagnosed, but in that series only the direct FA method was used and only the results at the first visit to the clinic were considered. Thus, the addition of the 
delayed FA method and repeated examinations provided a useful increase in the proportion of patients diagnosed in this series.

Catterall (1969) studied a group of women who attended a venereal diseases department complaining of vaginal discharge. Those not diagnosed at their first visit were asked to attend again, and when necessary four examinations were carried out as in our series. Catterall diagnosed gonorrhoea in relatively fewer women at their first visit and relatively more at later visits, but he used only Gram-stained smears and cultures. He studied a different group of patients so that his findings are not strictly comparable with ours, but they again illustrate the value of repeated examination in the diagnosis of gonorrhoea in women. Our findings suggest that when FA techniques are used three examinations are sufficient.

Ten of the fourteen patients in whom the infection was diagnosed after the first visit were secondary contacts who are unlikely to spread disease while awaiting diagnosis. Secondary contacts are often married women and there is always the risk of emotional and marital disturbance when such patients attend a venereal diseases clinic. Seale (1966), in a systematic assessment of married couples attending this department, found that emotional disturbance was usually greatest at the first visit and diminished thereafter. All our married patients and most of the other patients were seen by the Medical Social Worker, most cooperated well when the object of the repeated visits was explained to them, and there were no undue emotional upsets.

At the first visit 125 cases were positive by the delayed FA technique, 119 by the direct FA technique, 84 by $\mathrm{Gram}$-stained smears, and 85 by culture. Holman, Koornhof, and Hayden-Smith (1964) and Lind (1967) also found that the delayed FA technique gave more positive results than the other methods. On the other hand, Fry and Wilkinson (1964) reported more positive findings with the direct FA method than with the delayed method which gave slightly more positive results than Gramstained smears or cultures. McGill, Moffett, Masterton, and Schofield (1969) reported considerably fewer positive results by the delayed FA method than by Gram-stained smears and cultures. However, Reyn (1969) suggested that variability in the delayed method was probably due more to variation in culture media and techniques than to variation in the delayed FA staining method itself.

The results of our routine cultures were disappointing. We suspect that where plates had only a few colonies at 16 to $24 \mathrm{hrs}$ ' incubation all the material was removed for the delayed FA method. Thayer and Martin (1966) observed that gonococci appeared to grow faster on their selective medium than on ordinary media. Selective media are currently being studied in our laboratory and it is hoped to increase the number of positive routine cultures.

The direct FA staining method was introduced in this department to assist in rapid diagnosis. Although staining these smears is simple, we agree with Reyn (1969) that reading them can be tedious and timeconsuming. Furthermore, lengthy training is necessary to read the smears accurately. Delayed FA smears, which are stained by the same method, are much easier to read and the necessary training is correspondingly shorter. Although the results of the delayed method are only available on the day after a patient attends the clinic, this technique is very much easier to start in a department and it is less time-consuming for routine investigation. In addition, it may be more sensitive than other diagnostic methods as our results show.

\section{Summary}

Direct and delayed immunofluorescent methods as well as conventional smears and cultures were applied routinely in the examination of 157 female patients who had recently had contact with a mano suffering from gonorrhoea. The "delayed" fluorescent antibody (FA) technique gave more positive results than the direct FA method, which in turn gave more positive results than Gram-stained smears or cultures. Delayed FA smears were easier to read than direct FA smears. Patients whose infections were not diagnosed at the first visit attended up to four times for further investigation; cases diagnosed at the second or third visit were positive by FA studies alone. 144 out of 157 patients $(91 \cdot 1$ per cent.) were found to be suffering from gonorrhoea, the diagnosis being made at the first examination in 130 cases. It was concluded that when using FA methods a total of three sets of examinations is probably sufficient. Most cases diagnosed at the first visit were found in primary contacts but most diagnosed at subsequent visits were found in secondary contacts.

\section{References}

CATTERALL, R. D. (1969) WHO/VDT/60.363

Deacon, W. E., Peacock, W. L., Freeman, E. M., and Harris, A. (1959) Proc. Soc. exp. Biol. (N.Y.), 101, 322

- - - - - - and Bunch, W. L. (1960) Publ. Hlth Rep. (Wash.), 75, 125

FRY, C. S., and WILKINSON, A. E. (1964) Brit. F. vener. Dis., 40, 125

HARE, M. J. (1969) Paper read to M.S.S.V.D. on April 25, 1969

Holman, M. S., Koornhof, H. J., and Hayden-SMith, S. (1964) S. Afr. F. Lab. clin. Med., 10, 95 
LIND, I. (1967) Acta. path. microbiol. scand., 70, 613

MCGill, M. I., MoffetT, M., MASTERTON, G., and Schofield, C. B. S. (1969) Scot. med. F., 14, 176 ReYN, A. (1969) Bull. Wld Hlth Org., 40, 245

Seale, J. R. (1966) Brit. F. vener. Dis., 42, 31
Scott, J., and Stone, A. H. (1966) Ibid., 42, 103

Thayer, J. D., and Martin, J. E., Jr (1966) Publ. Hlth Rep. (Wash.), 81, 559

Thin, R. N. T. (1970) Brit. F. vener. Dis., 46, 27 